Short Communication

\title{
IM PACT OF A NOVEL METHOD OF TEACHING ANATOMY OF THE MALE PERINEUM ON THE UNDERGRADUATE MEDICAL STUDENTS
}

\author{
Snigdha Mishra', Satheesha Nayak B. ${ }^{2} \&$ Bincy M. George ${ }^{3}$ \\ ${ }^{1}$ Lecturer, ${ }^{2}$ Professor\& HOD, ${ }^{3}$ AssistantProfessor, Department of Anatomy, M elaka M anipal Medical College (M anipal \\ Campus), International Centre for Health Sciences, Madhav Nagar, M anipal, Udupi, Karnataka, INDIA \\ Correspondence: \\ Snigdha Mishra \\ Lecturer, Department of Anatomy, M elaka Manipal M edical College (M anipal Campus) \\ International Centre for Health Sciences, M adhav Nagar, M anipal - 576 104. Udupi, Karnataka, India \\ Mobile : +919886241582
}

\begin{abstract}
:
It is indeed a challenge to teach the cadaveric anatomy of the perineum to the undergraduate medical students. The anatomy teacher often fails to make the student understand the exact arrangement and attachments of the fasciae in the perineum in spite of his/her best attempts in the dissection hall and lecture classes. We prepared a video to demonstrate the arrangements of fasciae in the male perineum. The video had a combination of clips of cadaveric dissection, diagrams drawn on a blackboard and the demonstration of the arrangement of fasciae using a simple cloth model. The video was shown to students after they had the routine dissection and lecture classes about the perineum. There was a significant difference between the pre and post test scores. The opinion survey also indicated that the video was very effective.
\end{abstract}

Keywords: Anatomy of the perineum, Cloth model of perineum, teaching tool, medical students.

\section{Practice points:}

1). The traditional cadaveric dissection, though ideal for most of the anatomy teaching, may not be a very suitable tool in teaching the so called "difficult and challenging" areas like the perineum.

2). To bridge the gap between the available teaching tools and the challenges faced during teaching anatomy, there has been a constant pour of ideas in the form of models, diagrams and videos of dissection.

3). A combination of all the existing methods in the form of a video has been found to simplify the topic by the students

4). These kind of audio-visual aids have been testified by the students to be complementary to the traditional modes of teaching, and it completes the understanding of the subject by the students.

\section{Introduction:}

The knowledge of anatomy, plays an integral role in the education and practice of health care professionals( SergovichA et.al,2010). Most of the clinical skills and procedures require a thorough understanding of the spatial relationship between the adjacent structures of the human body (Garg et.al, Access this article online Quick Response Code

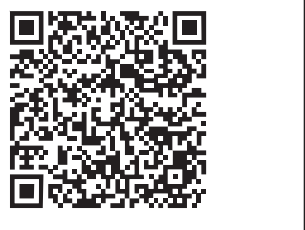

2001). In certain circumstances, the cadaveric dissection may not be an ideal tool for learning anatomy, and can be replaced by or enhanced by, tools like videos of cadaveric dissection or animated pictures (Mahmud W et.al, 2011). Viewing the video clips in anatomy among medical students has been reported to improve on comprehension of theoretical anatomy in them ( Pereira et.al, 2004). There is no 'the best method' for teaching or learning anatomy (Winkelmann, 2007). With our teaching experience in medical school for more than a decade we feel that there is a need to seek the best approach for teaching anatomy and to bridge the gaps in the existing tools.

The perineum is the region at the lower end of the trunk at the interval between the two thighs, where the external genitalia are located. It lies below the pelvic diaphragm. 
This region can be best exposed in lithotomy position (Snell RS, 2008). Study of the perineum in the dissected cadaver is difficult, because, it is a trouble some task to put the cadaver in the lithotomy position, the structures found in the perineum are very small and it is difficult to dissect and display the exact attachments of the fasciae in the perineal region. To overcome this, assistance in the form of diagrams can be used in Microsoft PowerPoint(PPT) or chalk board teaching (Sahu DR, 2000). But as the diagrams fail to provide $3 \mathrm{D}$ view of the perineal region, an average medical student finds it difficult to understand the complexity in the arrangement of the fasciae and structures in the region. Though we combine the dissection of the perineum in the laboratory for a batch of 16 students and the lecture class for the entire batch of medical students together (135 students), with the help of PPT and chalk board; students complain about the lack of understanding the anatomy of the perineal region. Therefore we aimed to develop a simple model of the perineum with a bony pelvis, colored cloth and wires to represent different fasciae and the contents of the perineal spaces.

Regional gross anatomy is better studied with sagittal and coronal sections to understand the relations of the closely arranged viscera and their clinical relevance. So, we attempted to produce an audio-visual aid in the form of a video with a combination of dissection of the perineum, simple drawings of coronal and sagittal sections of perineum with pelvis on chart papers and the demonstration of the simple 3D model of the perineum developed byus.

\section{Materials and method:}

1.) Dissection video

A male cadaver was tied in lithotomy position, and dissection was done to expose the boundaries and contents of the perineum. The entire procedure was video graphed and edited to obtain the key points of the entire dissection of the region.

2.) $2 \mathrm{D}$ images of sagittal and coronal sections of the perineum
Sagittal and the coronal sections of a male perineum with its contents were drawn in two different $3 \times 2$ feet white chart papers. The fasciae and the contents of the perineum were colored differently to differentiate them clearly. Ultimate care was taken to depict original human anatomy with the help of Cunningham's manual of practical anatomy, volume 2. Every structure was assigned a single color code for both the section diagrams and the chart papers were pasted to the wall. With the help of a pointer the boundaries, contents and clinical importance of the region was spelled out and video graphed at an optimum and uniform pace.

\section{3.) 3D model of a male perineum}

3D model of a male perineum was designed and created with a male pelvis and different colored cloth, which were cut and stitched to mimic the normal anatomy of the male perineum. Muscles were tailored using dark red cloth and urethra was shown using a black wire. The model was demonstrated at an optimum pace and video graphed.

All the above three videos were tailed with narrations using Windows M ovie M aker 2007.

\section{4.) Questionnaire study}

Students of Batch 28 of Melaka Manipal Medical College, Manipal, India, were taught the regional anatomy of the perineum in the traditional way of dissection and the lecture classes to explain the boundaries, contents and applied aspects of the perineum. A test was conducted following it to assess their anatomical knowledge(for volunteers only, $n=126$ ), with the help of 5 A-type (single best response) multiple choice questions (Pre Test). Following this, the newly developed audio-visual aid of 20 minutes duration was projected in the class room with the help of the overhead LCD projector and a Post- Test was given, same as that of the Pre- Test, at its conclusion. Along with the pre and post-tests, a structured questionnaire about students' perception of their understanding of the anatomy of the perineum was also given. The students were instructed to mention their roll 
numbers in the answer scripts, so that a comparative statistical analysis could be done for the pre and posttests. The statements in the pretest survey were as follows:

I I have understood the attachment of perineal membrane clearly

I I know how the superficial and deep perineal pouches are placed in our body

I I know the positions and attachments of the fasciae in the urogenital triangle of a male

I I can trace the scarpa'a fascia of the anterior abdominal wall to the perineum

I I know the path taken by extravasated urine in case of rupture of spongy urethra

The students were asked to rank the above 5 comments on a 5 point scale of Likert's, ie, 5- strongly agree, 4- agree, 3uncertain, 2-disagree, 1- strongly disagree.

The data was analysed using paired t-test using Prism Statistical software.

Along with the post test, the students were also asked to fill the following structured questionnaire about their views and perception of the audio-visual material of the perineum. The statements in the post-test opinion surveywere asfollows:
1 The audiovisual material gave me a better idea about theurogenital region

I The audio visual material was self-explanatory

I The objectives and audio quality were appropriate

1 The model used in the material was simple

I The content of audio visual material was adequate for understanding the attachment of the fasciae in the region

The students were asked to rank the above 5 comments on a 5 point scale of Likert's, ie, 5- strongly agree, 4- agree, 3uncertain, 2-disagree, 1- strongly disagree.

The mean score of the data from the above statements was calculated.

\section{Results:}

A) Comparison of pre and post test scores:

126 students participated in both pre and post-test. Among them 101 students scored better in post-test. Out of this 28 students who had scored low (i.e., 0 , 1or 2 out of 5) in pre-test scored very good in post-test (i.e., 4 or 5). 13 out of 126 students, scores maximum (i. ie, 5 marks) in both pre and post-test. Paired t-test to compare the data of pre and post-test was done using Prism Statistical software and the results are tabulated below:.

B) Students perception of understanding about perineum before and after the intervention of the video:

\begin{tabular}{|l|c|c|c|c|}
\hline $\begin{array}{l}\text { Total Number of Students participated } \\
\text { in Pretest\& Post test }\end{array}$ & $\begin{array}{c}\text { Mean Pre } \\
\text { Test Score }\end{array}$ & $\begin{array}{c}\text { Mean Post } \\
\text { Test Score } \\
\text { (SEM) }\end{array}$ & $\begin{array}{c}\text { P value } \\
\text { (two tailed) } \\
\text { (SEM) }\end{array}$ & $\begin{array}{c}\text { Number of students } \\
\text { who scored better } \\
\text { in post test (\%) }\end{array}$ \\
\hline 126 & $2.97(0.11)$ & $4.41(0.07)$ & $<0.0001$ & $101(80.2 \%)$ \\
\hline
\end{tabular}

Table 1: Comparison of means of pre and post test scores

\begin{tabular}{|c|c|c|c|c|}
\hline Statements & $\begin{array}{c}\text { Mean Pre } \\
\text { Test Scores (SEM) }\end{array}$ & $\begin{array}{c}\text { Mean Post } \\
\text { Test Scores (SEM) }\end{array}$ & $\begin{array}{l}\text { Paired difference } \\
\text { in mean scores }\end{array}$ & $\begin{array}{c}\text { P value } \\
\text { (two tailed) }\end{array}$ \\
\hline $\begin{array}{l}\text { 1. I have understood the attachment of perineal } \\
\text { membrane clearly }\end{array}$ & $\begin{array}{c}2.96 \\
(0.08)\end{array}$ & $\begin{array}{c}4.08 \\
(0.05)\end{array}$ & 1.12 & $\varangle .0001$ \\
\hline $\begin{array}{l}\text { 2. I know how the superficial and deep perineal } \\
\text { pouches are placed in our body }\end{array}$ & $\begin{array}{c}3.41 \\
(0.09)\end{array}$ & $\begin{array}{c}4.30 \\
(0.06)\end{array}$ & 0.89 & $\varangle .0001$ \\
\hline $\begin{array}{l}\text { 3. I know the positions and attachments of the } \\
\text { fasciae in the urogenital triangle of a male }\end{array}$ & $\begin{array}{c}3.04 \\
(0.08)\end{array}$ & $\begin{array}{c}4.07 \\
(0.07)\end{array}$ & 1.03 & $\varangle 0.0001$ \\
\hline $\begin{array}{l}\text { 4. I can trace the scarpa'a fascia of the anterior } \\
\text { abdominal wall to the perineum }\end{array}$ & $\begin{array}{c}3.10 \\
(0.09)\end{array}$ & $\begin{array}{c}4.14 \\
(0.06)\end{array}$ & 1.04 & $\varangle .0001$ \\
\hline $\begin{array}{l}\text { 5. I know the path taken by extravasated urine in case } \\
\text { of rupture of spongy urethra }\end{array}$ & $\begin{array}{c}3.23 \\
(0.09)\end{array}$ & $\begin{array}{c}4.39 \\
(0.05)\end{array}$ & 1.16 & $\varangle .0001$ \\
\hline
\end{tabular}

Table 2: Change in students' perception of understanding before and after the intervention 
From the above table (Table 2) it is clear that the audiovisual material was useful for the students' understanding about the anatomy of the perineum. Qualitative comments written by the students also showed the level of understanding of the students improved after the video. The comments are as follows.

1). "Thank you! It was a very hard topic until the video": (4 students)

2). "Excellent job" / "the video is awesome"/ "very effective and helpful": (7 students)

3). "We want more videos like this": (5 students)

4). "dissection part of the video is good" / "Good"| "good effort": (5 students)

5). "It's a good practice for revision. Schematic diagrams and models are very creative and easy to understand"

6). "The image is definitely clear. Ever one has a clear vision on the specimen. Enough time to observe the specimen. All these are not there in the dissection class but are there in the video"

C). Students' perception about the quality and the effectiveness of the audio-visual aid:

The average score on Likert's scale regarding the quality and effectiveness of the video for all the five statements ranged between 4 to 5 ( Table 3 )

\begin{tabular}{|c|c|}
\hline Statements & $\begin{array}{c}\text { Average Scores } \\
\text { (Likert's scale) } \\
n=126\end{array}$ \\
\hline $\begin{array}{l}1 \text { The audiovisual material gave me a better } \\
\text { idea about the urogenital region }\end{array}$ & 4.37 \\
\hline $\begin{array}{l}\text { 2. The audio visual material was } \\
\text { self-explanatory }\end{array}$ & 4.10 \\
\hline $\begin{array}{l}\text { 3. The objectives and audio quality } \\
\text { were appropriate }\end{array}$ & 4.31 \\
\hline 4 The model used in the material was simple & 4.36 \\
\hline $\begin{array}{l}\text { 5. The content of audio visual material was } \\
\text { adequate for understanding the } \\
\text { attachment of the fasciae in the region }\end{array}$ & 4.22 \\
\hline
\end{tabular}

Table 3: Students' perception about the quality and effectiveness of the audio-visual aid

\section{Discussion:}

Many models of female pelvis focus primarily on the pelvic diaphragm were created and used in medical education. But most of them failed to acknowledge the boundaries and contents of the perineum (Beyersdorff D et.al., 2001; Sergovich A et.al., 2010). Our study material is unique as this is a very simple and a reproducible one. Anatomy of the perineum was explained extensively and in totality, in a simple way to reach out to the average and below average students, in our medical school, by the developed aid. The pre and post test scores, students' perception of the effectiveness of the aid and the clear statistical significance, clearly highlights that our study material is very effective.

The medical students of M elaka M anipal M edical College, Manipal, India, significantly preferred the audio-visual material than the traditional teaching. Although, one student commented that, " the video can be a supplementary tool rather than replacing the traditional teaching methods with it". We feel this comment is considerable, as, the mean Likert's scale score of the questionnaire regarding the understanding of the anatomy of perineum before the video was shown, was around 3, indicating that most of the students had some idea about the perineal anatomy.

Some authors havesuggested that, it is better to implement teaching techniques, including 3D models after investigating their effectiveness as a teaching tool (Patel and Moxham, 2008). Here we have tried to test the effectiveness of the aid on the students, before it is used as a successful teaching tool. Earlier researchers have studied the students' perception of various lecture delivery methods like chalk board teaching and lectures with the help of overhead projectors and PPTs (Seth V et.al., 2010). There are studies to test the effectiveness of videos and 3D models separately, and they found it important to provide information to students (Hartsel T and Yuen S, 2006; Health Cet.al., 2007), but less attention has been given to the complicated areas, on the scale of understanding, such as perineum. To the best of our knowledge and literature 
search, we could not find any one study that combined the real cadaveric dissection, 3D model and 2D pictures in of sagittal and coronal sections, for the better understanding of the orientation of the structures in the perineum.

\section{Conclusion:}

The perineum is the challenging region of human anatomy. It is very difficult to conceptualise the $3 \mathrm{D}$ picture of

\section{References:}

1. Beyersdorff D, Schiemann T, Taupitz M, Kooijman H, Hamm B, Nicolas V.2001. Sectional depiction of the pelvic floor by CT, M R imaging and sheetplastination: Computer-aided correlation and 3D model. EurRadiol 11:659-664.

2. Garg AX, Norman G, Sperotable L. 2001. How medical students learn spatial anatomy. Lancet 357:363-364.

3. Hartsell T, Yuen S. Video streaming in online learning. Association for the Advancement of Computing (AACE) Journal.2006; 14(1):31-43.

4. Health C, Luff P, Sanchez M . Video and qualitative research: analyzing medical practice and interaction. Medical Education. 2007; 41:109116.

5. M ahmud W, Hyder O, Butt J, AftabA.Dissection Videos Do Not Improve Anatomy Examination Scores AnatSciEduc 4:16-21 (2011)

6. Patel KM, Moxham BJ. 2008. The relationships between learning outcomesand methods of teaching anatomy as perceived by professional anatomists.ClinAnat 21:182-189.

7. Pereira JA, M erı' A, Masdeu C, M olina-Toma' s MC, M artı́nez-Carrio' A. 2004.Using video clips to improve theoretical anatomy teaching. EurJ Anat 8:143-146.

8. Romanes GJ, Cunningham's M anual of practical Natomy; Volume Two, Thorax and Abdomen, $15^{\text {th }}$ Edition Oxford University press: $\mathrm{p} / 199$; 2000.

9. Sahu DR, Supe AN. The art and science of presentation: 35-mm slides. J Postgrad M ed. 2000;46:280-285.

10. Sergovich A, Johnson M, Wilson T D. Explorable Three-Dimensional Digital Model of theFemalePelvis, Pelvic Contents, and Perineum for Anatomical Education; AnatSciEduc 3:127-133 (2010)

11. Seth V, Upadhyaya P, Ahmad M , M ogheV.PowerPoint or chalk and talk: Perceptions of medical students versus dental students in a medical college in India. Advances in Medical Education and Practice 2010:1 11-16.

12. Snell RS, Clinical Anatomy by Regions; $8^{\text {th }}$ Edition Lippincott Williams and Wilkins: p/388-401;2008

13. Winkelmann A. 2007. Anatomical dissection as a teaching method in medical school: A review of the evidence. M ed Educ 41:15-22. perineum for the beginner in anatomy, like the undergraduate medical students. A digital anatomical teaching tool with the combination of dissection, 2D diagrams and the demonstration of the 3D model of perineum, enhances the understanding/ learning of the anatomy of the perineum. 